\title{
A Modified Version of the Unique Cue Theory Accounts for Olfactory Compound Processing in Honeybees
}

\author{
Nina Deisig, ${ }^{1}$ Harald Lachnit, ${ }^{2,4}$ Jean-Christophe Sandoz,${ }^{3}$ Klaus Lober,${ }^{2}$ and \\ Martin Giurfa ${ }^{3}$ \\ ${ }^{1}$ Neurobiology, Institute of Biology, Free University of Berlin, D-14195 Berlin, Germany; ${ }^{2}$ Fachbereich Psychologie, Philipps-Universität Marburg, \\ D-35032 Marburg, Germany; ${ }^{3}$ Centre de Recherches sur la Cognition Animale, CNRS-Université Paul-Sabatier, 31062 Toulouse cedex 04, \\ France
}

\begin{abstract}
We investigated the capability of honeybees to discriminate between single odorants, binary olfactory mixtures, and ternary olfactory mixtures in olfactory conditioning of the proboscis extension reflex. In Experiment 1, three single odorants $(\mathrm{A}+, \mathrm{B}+$, and $\mathrm{C}+$ ) and three binary mixtures of these odors $(\mathrm{AB}+, \mathrm{AC}+$, and $\mathrm{BC}+$ ) were reinforced while the ternary compound, consisting of all three odors (ABC-), was nonreinforced. In Experiment 2, only one single odorant $(\mathrm{A}+)$ and one binary olfactory compound $(\mathrm{BC}+)$ were reinforced while the ternary compound $(\mathrm{ABC}-)$ consisting of the single odor and the binary compound was nonreinforced. We studied whether bees can solve these problems and whether the course of differentiation can be predicted by the unique cue theory, a modified unique cue theory, or Pearce's configural theory. Honeybees were not able to differentiate reinforced from nonreinforced stimuli in Experiment 1. However, summation to $\mathrm{ABC}$ observed at the beginning of training contradicts the predictions of Pearce's configural theory. In Experiment 2, differentiation between the single odorant A and the ternary compound developed more easily than between the binary compound $\mathrm{BC}$ and $\mathrm{ABC}$. This pattern of differentiation is in line with a modified unique cue theory and Pearce's configural theory. Summation to ABC at the beginning of training, however, again was at odds with Pearce's configural theory. Thus, olfactory compound processing in honeybees can best be explained by a modified unique cue theory.
\end{abstract}

The processing of stimuli composed of more than one single element (compounds) is of major interest but has not been clearly elucidated up to now (e.g., Rowe 1999; Pearce and Bouton 2001). Two main approaches, an "elemental" and a "configural" one, have been proposed to explain compound processing. The former assumes that animals are able to extract the elemental composition of the compound, whereas the latter postulates that animals process a compound as a new configuration, independently of its single stimuli. Among elemental theories, the pure elemental theory is the most simple and supposes that the total associative strength ( $V$ ) of a compound $\mathrm{AB}$ results from the mere summation of the associative strengths of its elements A and $\mathrm{B}$ (i.e., $V_{\mathrm{AB}}=V_{\mathrm{A}}+V_{\mathrm{B}}$ ). For each stimulus, the change in associative strength, $\Delta V$, results from the model of Rescorla and Wagner (1972):

$$
\Delta V=\alpha * \beta *\left(\lambda-V_{\mathrm{T}}\right)
$$

${ }^{4}$ Corresponding author.

E-MAIL Lachnit@staff.uni-marburg.de; FAX 4964212826621. Article and publication are at http://www.learnmem.org/cgi/doi/ 10.1101/lm.55803. where $\Delta V$ is the change in associative strength $V, \alpha$ is the learning rate associated with the stimulus under consideration $(\mathrm{A}, \mathrm{B}$, or $\mathrm{AB}), \beta$ is the learning rate associated with the reinforcement, $\lambda$ is the asymptotic level of associative strength that can be supported by the reinforcement, and $V_{\mathrm{T}}$ is the combined associative strengths of all stimuli present on a learning trial. An extension of the elemental theory is the unique cue theory, which assumes that a compound $\mathrm{AB}$ is processed as the sum of the single elements $\mathrm{A}$ and $\mathrm{B}$, plus a stimulus $\mathrm{U}$, which is unique to the compound and results from the conjunction of $\mathrm{A}$ and $\mathrm{B}$ (i.e., $V_{\mathrm{AB}}=V_{\mathrm{A}}+V_{\mathrm{B}}+V_{\mathrm{U}}$; Rescorla 1972, 1973; Whitlow and Wagner 1972).

Among configural theories, on the other hand, Pearce's configural theory assumes that the elements of a compound collectively enter into a single association (e.g., Pearce $1987,1994)$. Thus, no summation of the single associative strengths occurs. However, if stimuli share common elements, generalization will occur between them. The degree of generalization will depend on the number of common elements (e.g., there will be generalization between $A B$ and A or B, but not between A and B). Finally, an "extreme" configural theory was also proposed, which retains the assumption of Pearce's configural theory but pushes its phi-

LEARNING \& MEMORY 10:199-208 @ 2003 by Cold Spring Harbor Laboratory Press ISSN1072-0502/03 \$5.00

$$
\begin{array}{lllllllllllllll}
L & E & A & R & N & I & N & G \quad & \mathbf{Z} & M & E & M & O & R & Y \\
\text { www.learnmem.org } & & &
\end{array}
$$


losophy to the extreme by postulating that a compound is coded as a new stimulus ("Gestalt") that is totally unrelated to its elements. As a consequence, no generalization should occur between a compound and its elements (for a comparison between configural and extreme configural points of views, see Williams and Braker 1999).

Negative patterning is a discrimination problem that is particularly interesting for comparing elemental and configural theories. In this task, animals have to learn to respond to two single reinforced stimuli $(\mathrm{A}+, \mathrm{B}+)$ but not to their compound, which is nonreinforced ( $\mathrm{AB}-)$. Negative patterning cannot be solved through pure elemental processing, as summation of the elemental excitatory strengths on compound presentation would always result in stronger responding to the compound than to the elements. As solving a negative patterning discrimination is incompatible with the pure elemental theory, the unique cue theory has been invoked to explain such discrimination. It assumes that the unique cue (U) becomes sufficiently inhibitory to block responding to the elements on compound presentation. Configural theories, on the other hand, can account for negative patterning discrimination. If animals perceive a compound as a new configuration that is distinct from its elements, then differentiation between elements and the compound is straightforward (Pearce 1987, 1994).

Recently, we have shown that honeybees, Apis mellifera $\mathrm{L}$., are able to solve negative patterning both in the olfactory and in the visual domain (Deisig et al. 2001, 2002; Schubert et al. 2002). In the olfactory domain, experiments were performed using classical conditioning of the proboscis extension reflex (PER; Takeda 1961; Bitterman et al. 1983). In such a paradigm, bees learn to associate an odor presented to the antennae (conditioned stimulus or CS) with a reinforcement of sucrose solution (unconditioned stimulus or US) delivered to the proboscis. They thus learn to extend their proboscis to the mere presentation of the odor. Using this paradigm, we showed that bees solved negative patterning, a fact that allowed dismissing the pure elemental theory as an explanation for compound processing (Deisig et al. 2001). Furthermore, a certain amount of generalization between elements and compounds was found, a fact that allowed discarding the extreme configural theory, according to which generalization should never occur. We also showed that a reduction of similarity between a compound and the elements enhances the degree to which animals discriminate between both kinds of CSs (Deisig et al. 2002). Thus, discrimination was better in an $\mathrm{CD}-$ versus $\mathrm{A}+, \mathrm{B}+$ task than in an $\mathrm{AB}-$ versus $\mathrm{A}+, \mathrm{B}+$ task. Discrimination in an $\mathrm{AC}-$ versus $\mathrm{A}+, \mathrm{B}+$ task was intermediate. Both the unique cue theory and Pearce's configural theory could account for the acquisition of the three tasks (Deisig et al. 2002). However, bees trained with the A+, B+ versus $\mathrm{AB}-$ discrimination, and then tested with a novel compound $\mathrm{BC}$ after training, showed stronger responding to $\mathrm{BC}$ than to $\mathrm{B}+$. This finding was not predicted by Pearce's configural theory (Deisig et al. 2002)

Although our results indicate that olfactory compound processing in bees relies on the use of unique cues, two lines of evidence make it worth reconsidering this possibility. Firstly, results from studies in other species (e.g., pigeons, rabbits) contradict it because they support the idea that stimuli of the same modality (intramodal) favor the emergence of configural rather than elemental associations (e.g., Pearce and Redhead 1993; Redhead and Pearce 1995; Rescorla and Coldwell 1995; Pearce et al. 1997), whereas stimuli of different modalities (intermodal) favor the emergence of elemental associations (e.g., Bahçekapili 1997; Myers et al. 2001). Our experiments on negative patterning in bees used intramodal stimuli (odors) but nevertheless were in support of the elemental unique cue theory. The present experiments were thus conceived to provide further empirical assessment of these alternative accounts. Secondly, in our previous studies we neglected the problem that in olfactory PER conditioning of honeybees the conditionability of odorants may be reduced in mixtures. The experiments on overshadowing by Smith (1996) may be interpreted as reflecting interferences between the components of an odor mixture.

As such interference is not taken into account neither by the unique cue theory nor by Pearce's configural theory, we additionally have now considered the so-called modified unique cue theory (Redhead and Pearce 1995). This theory predicts that conditioning of a single reinforced element progresses in the manner predicted by the Rescorla and Wagner equation (see equation 1; Rescorla and Wagner 1972) but states that in the case of compound conditioning, the presence of one element restricts learning about the other, thus yielding a slower rate of learning for the compound. In this case, the change $\left(\Delta V_{\mathrm{A}}\right)$ in associative strength of an element $\mathrm{A}$ belonging to an $\mathrm{AB}$ compound results from:

$$
\Delta V_{\mathrm{A}}=\alpha_{\mathrm{A}} * \alpha_{\mathrm{A}} / \alpha_{\mathrm{T}} * \beta *\left(\lambda-V_{\mathrm{T}}\right)
$$

where $\alpha_{\mathrm{T}}$ is determined by the combined salience of all stimuli present $\left(\alpha_{\mathrm{T}}=\alpha_{\mathrm{A}}+\alpha_{\mathrm{B}}\right)$. Interestingly, our previous findings (Deisig et al. 2001; 2002) are consistent with the modified unique cue theory.

To further decide between the modified unique cue theory, the unique cue theory, and Pearce's configural theory, we performed two experiments involving single odorants and binary and ternary odor mixtures, based on a study by Redhead and Pearce (1995) on visual conditioning of pigeons. In a first experiment, bees had to learn to respond to the single odorants $(\mathrm{A}+, \mathrm{B}+, \mathrm{C}+)$ and the binary mixtures $(\mathrm{AB}+, \mathrm{AC}+, \mathrm{BC}+)$ but not to the ternary mixture $(\mathrm{ABC}-)$. In a second experiment, they had to learn to respond to a single odorant $\mathrm{A}+$ and the binary mixture $\mathrm{BC}+$ but not to the ternary mixture ABC-.

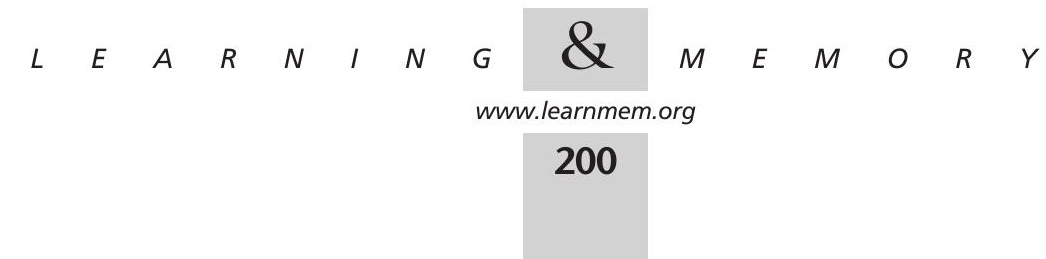


In the first experiment, Pearce's configural theory predicts a better differentiation between $\mathrm{A}+/ \mathrm{B}+/ \mathrm{C}+$ and $\mathrm{ABC}-$ than between $\mathrm{AB}+/ \mathrm{AC}+/ \mathrm{BC}+$ and $\mathrm{ABC}-$. This is because of the idea that binary compounds support more generalization to $\mathrm{ABC}$ - (and vice versa) than single elements, as the former have more elements in common with the ternary compound. Contrarily, the unique cue theory predicts better differentiation between $\mathrm{AB}+/ \mathrm{AC}+/ \mathrm{BC}+$ and $\mathrm{ABC}-$ than between $\mathrm{A}+/ \mathrm{B}+/ \mathrm{C}+$ and $\mathrm{ABC}-$, as the single associative strengths sum up upon compound presentation. Because of such a summation, responses should be stronger for the binary compounds than for the single elements. The modified unique cue theory also predicts stronger responding to binary compounds than to single elements (for a more detailed discussion, see Redhead and Pearce 1995). In the second experiment, according to the unique cue theory, one expects a better differentiation between $\mathrm{BC}+$ and $\mathrm{ABC}-$ than between $\mathrm{A}+$ and $\mathrm{ABC}$ - because of summation of the associative strengths of $\mathrm{B}$ and $\mathrm{C}$ upon binary compound presentation. Conversely, Pearce's configural theory and the modified unique cue theory predict that differentiation between $\mathrm{A}+$ and $\mathrm{ABC}$ - should be better than that between $\mathrm{BC}+$ and $\mathrm{ABC}-$. For Pearce's configural theory this is caused by the higher degree of generalization between the $\mathrm{AB}+$ and the $\mathrm{ABC}$ - compounds (more elements in common), which renders this discrimination difficult. For the modified unique cue theory, the presence of one stimulus restricts learning about the other on reinforced compound trials $(\mathrm{BC}+)$, and this results in a slower rate of conditioning for this compound. However, the two theories differ in their prediction of summation at the beginning of training. For Pearce's configural theory, no summation should occur upon compound presentation. For the modified unique cue theory, summation is possible. Thus, the two experimental designs used in this work allow us to decide among the unique cue, the modified unique cue, and Pearce's configural theories.

\section{RESULTS}

\section{Experiment 1: $\mathrm{A}+/ \mathrm{B}+/ \mathrm{C}+$ and $\mathrm{AB}+/ \mathrm{AC}+/ \mathrm{BC}+$ Versus ABC -}

Figure 1 shows the responses (\% PER) of the bees to the stimuli $\mathrm{A}+/ \mathrm{B}+/ \mathrm{C}+, \mathrm{AB}+/ \mathrm{AC}+/ \mathrm{BC}+$, and $\mathrm{ABC}-$ grouped in blocks. For the reinforced single stimuli $(A+/ B+/ C+)$, each block consisted of one presentation of each stimulus (i.e., each block contains three trials); for the binary compounds $(\mathrm{AB}+/ \mathrm{AC}+/ \mathrm{BC}+)$, each block also consisted of one presentation of each mixture (i.e., each block has also three trials); for the ternary mixture (ABC-), each block consisted of six presentations of the nonreinforced compound. Blocks 1 and 2 show responding during the first day of conditioning, whereas blocks 3 and 4 show responding during the second day.

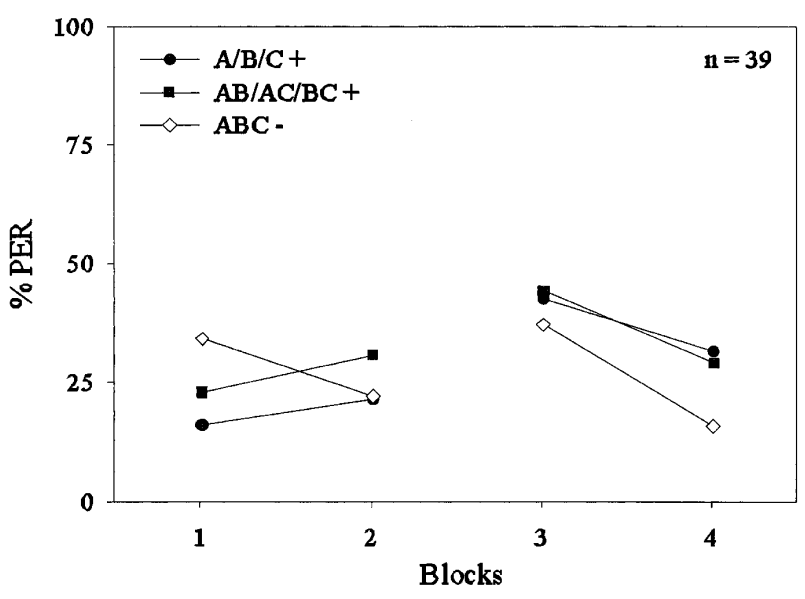

Figure 1 Conditioned proboscis extension response (\% PER) along trials in an $A+/ B+/ C+$ and $A B+/ A C+/ B C+$ versus $A B C-$ discrimination. The curve depicts the course of \% PER to the reinforced single elements $\mathrm{A}+, \mathrm{B}+$, and $\mathrm{C}+(-)$; the reinforced binary compounds $\mathrm{AB}+\mathrm{AC}+$, and $\mathrm{BC}+(\mathbf{\square})$; and the nonreinforced ternary compound $\mathrm{ABC}-(\diamond)$ during acquisition along four blocks of training. For the single elements and the binary compounds, each block consists of the averaged response to all three elements or binary compounds on the given trial. For the ternary compound, each block consists of six sequential trials.

A $3 \times 4$ ANOVA for the complete training (both days) including the factors trial type and block revealed no significant effect of trial type $(F<1)$. However, the trial type $\times$ block interaction was significant $\left(F_{6,342}=3.48\right.$, $p<0.01$ ), indicating that the amount of responding to reinforced and nonreinforced trial types changed across blocks of trials. Furthermore, the main effect of block as well was significant $\left(F_{3,342}=12.47, p<0.01\right)$, indicating that responses on average changed across blocks of trials. On block 1 , trials differed significantly $\left(F_{2,114}=3.63, p<0.05\right)$. A Newman-Keuls post hoc comparison revealed that responses to the ternary compound $\mathrm{ABC}-$ were significantly stronger than responses to the single elements $\mathrm{A}+\mathrm{B}+/ \mathrm{C}+$. Responses to the binary compounds $\mathrm{AB}+/ \mathrm{AC}+/ \mathrm{BC}+$ did not differ significantly from those to the ternary compound ABC-.

A separate analysis of the two training days revealed that responding to reinforced versus nonreinforced trials differed neither on day 1 nor on day $2(3 \times 2$ ANOVA, day 1: $F_{2,114}=1.33, p>0.05$; day $\left.2: F_{2,114}=1.45, p>0.05\right)$. However, the trial type $\times$ block interaction was significant on the first day of training $\left(F_{2,114}=4.99, p<0.01\right)$, but the main effect of block was not $\left(F_{1,114}=0.01, p>0.05\right)$, indicating that overall responses did not change over blocks. On the second day of training, only the main effect of block was significant $\left(F_{1,114}=43.4, p<0.05\right)$, indicating that responses decreased over blocks, whereas the trial type $\times$ block interaction was not significant $\left(F_{2,114}=1.51\right.$, $p>0.05)$. An analysis of the last block of training revealed that bees did not learn to differentiate between the rein-

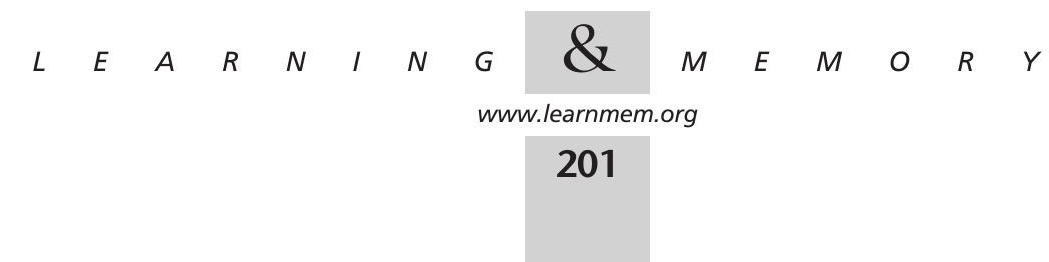


forced $\mathrm{A}+/ \mathrm{B}+/ \mathrm{C}+$ or $\mathrm{AB}+/ \mathrm{AC}+/ \mathrm{BC}+$ and the nonreinforced $\mathrm{ABC}-$ trials $\left(F_{2,114}=2.88, p>0.05\right)$. This means that on the basis of these results, it was impossible to decide between the competing theories of compound processing, which make different predictions about the differentiation between elements and mixtures.

Nevertheless, focusing on summation at the beginning of conditioning, it was possible to evaluate the theories. We therefore performed an analysis of the anticipatory responses to the second presentation of each kind of trial. For the single elements and binary compounds, this measured responding after one reinforced trial, whereas for the ternary compound, it measured responding after one nonreinforced trial. A one-way ANOVA revealed a significant effect of trial type $\left(F_{2,114}=3.89, p<0.05\right)$. A Newman-Keuls post hoc comparison revealed that responding to the ternary compound $\mathrm{ABC}-$ was significantly stronger than responding to the single stimuli $\mathrm{A}+/ \mathrm{B}+/ \mathrm{C}+$. Responding to the binary compounds $\mathrm{AB}+/ \mathrm{AC}+\mathrm{BC}+$ was not significantly lower than responding to the ternary compound $\mathrm{ABC}-$. Thus, summation during $\mathrm{ABC}$ - presentation occurred at the beginning of conditioning.

The pattern of results at the end of training does not allow a general conclusion with regard to the different theories of compound processing. Responding to the single stimuli did not differ from responding to the binary compounds. However, summation in block 1 was unexpected from the point of view of Pearce's configural theory but was in line with both the unique cue theory and the modified unique cue theory. As this experiment did not allow deciding in favor of a particular theory, we performed a second experiment in which a single element and a binary compound were reinforced $(\mathrm{A}+, \mathrm{BC}+)$ while their ternary mixture was not (ABC-).

\section{Experiment 2: $\mathrm{A}+$ and $\mathrm{BC}+$ Versus $\mathrm{ABC}-$}

Figure 2 shows the responses (\% PER) of the bees to the stimuli $\mathrm{A}+, \mathrm{BC}+$, and $\mathrm{ABC}-$ grouped into blocks. For the reinforced single stimulus $A+$, each block consisted of one presentation; for the binary compound $\mathrm{BC}+$, each block consisted of one presentation; and for the ternary mixture (ABC-), each block consisted of two presentations.

For both days of training, response differentiation between $\mathrm{A}+$ and $\mathrm{ABC}-$ was stronger than that between $\mathrm{BC}+$ and $\mathrm{ABC}-$. A $3 \times 6$ ANOVA for the complete training (both days) including the factors trial type and block revealed a significant effect of trial type $\left(F_{2,114}=4.86, p<0.01\right)$. The difference between reinforced and nonreinforced trial types increased across blocks of training. This was confirmed by the significant trial type $\times$ block interaction $\left(F_{10,570}=6.06, p<0.01\right)$. Furthermore, the main effect of block was significant as well $\left(F_{5,570}=15.55, p<0.01\right)$, indicating that on average, response proportions increased across blocks of trials. During the first block of training,

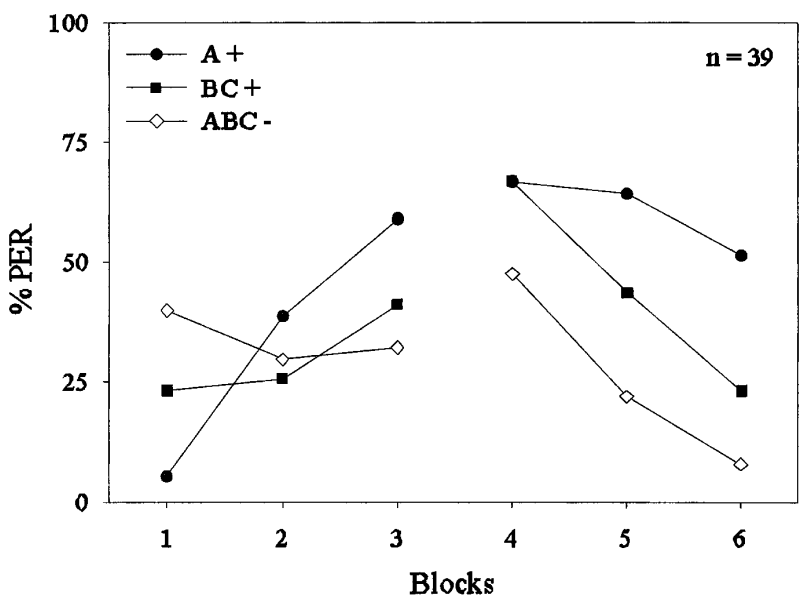

Figure 2 Conditioned proboscis extension response ( $\%$ PER) along trials in an $\mathrm{A}+$ and $\mathrm{BC}+$ versus $\mathrm{ABC}-$ discrimination. The curve depicts the course of $\%$ PER to the reinforced single element $\mathrm{A}+(\mathbf{)})$, the reinforced binary compound $\mathrm{BC}+(\mathbf{\square})$, and the nonreinforced ternary compound $\mathrm{ABC}-(\diamond)$ during acquisition along six blocks of training. For the single element and the binary compound, each block consists of one trial each, whereas for the ternary compound, each block consist of two sequential trials.

the response to the three stimuli differed significantly $\left(F_{2,114}=9.58, p<0.01\right)$. A Newman-Keuls test revealed that in the first block, responding to the ternary compound $\mathrm{ABC}-$ was significantly stronger than responding to the binary compound $\mathrm{BC}+$ or to the single element $\mathrm{A}+$. In block 2 , responses did not differ significantly. In block 3 , responses to A+ were significantly stronger than responses to $\mathrm{BC}+$ and $\mathrm{ABC}-\left(F_{2,114}=3.39, p<0.04\right)$. During the first block of training on day 2 (block 4 ), responding did not differ between any trial type $(F<1)$. In block 5 , responses were again significantly different $\left(F_{2,114}=8.86, p<0.01\right)$. Responding to A+ was strongest and differed significantly from responding to $\mathrm{ABC}-$, as well as from responding to $\mathrm{BC}+$. Responding to $\mathrm{BC}+$ was also significantly stronger than to ABC-. During the last block of training, responding to the different stimuli also varied significantly $\left(F_{2,114}=12.11, p<0.01\right)$. Responding to A+ was significantly stronger than responding to $\mathrm{BC}+$ and $\mathrm{ABC}-$, whereas responding to $\mathrm{BC}+$ and $\mathrm{ABC}-$ did not differ significantly.

Considering the two training days separately, no overall difference between reinforced and nonreinforced trial types could be found on day $1(3 \times 3$ ANOVA of day 1 : $\left.F_{2,114}<1\right)$. However, the main effect of block $\left(F_{2,228}=10.53\right.$, $p<0.01)$ and the trial type $\times$ block interaction $\left(F_{4,228}=7.8\right.$, $p<0.01)$ were significant. For the second day of training, there was a significant main effect of trial type $(3 \times 3$ ANOVA of day 2: $\left.F_{2,114}=11.62, p<0.01\right)$ as well as a significant main effect of block $\left(F_{2,228}=24.97, p<0.01\right)$. The trial type $\times$ block interaction was not significant $\left(F_{4,228}=2.2, p>0.05\right)$.

A Newman-Keuls test revealed that responses to $\mathrm{A}+$

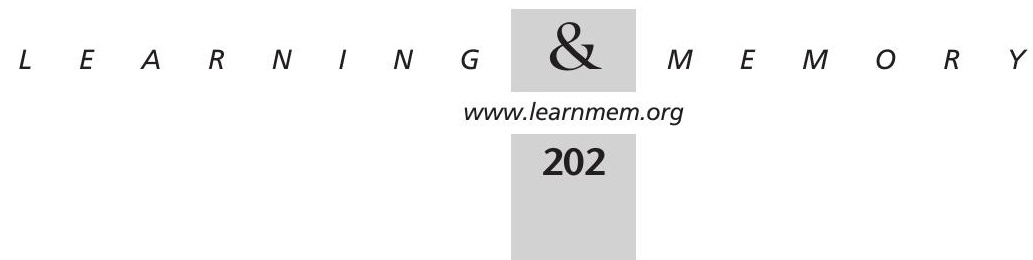


and $\mathrm{BC}+$ differed significantly in the first and last block of training. Responding to A+ was significantly weaker than to $\mathrm{BC}+$ in the first block, whereas this situation was reversed in the last block of training. Therefore, the results of this experiment clearly show that bees learned to differentiate between reinforced and nonreinforced stimuli. At the end of training, response differentiation between $\mathrm{A}+$ and $\mathrm{ABC}-$ was stronger than that between $\mathrm{BC}+$ and $\mathrm{ABC}-$. This finding is in contradiction to the unique cue theory. It is, however, in accordance with the predictions made by the modified unique cue theory and by Pearce's configural theory. Focusing on summation at the outset of training helps to decide between the remaining two theories. Responses to $\mathrm{ABC}-$ were significantly stronger than to $\mathrm{A}+$ and $\mathrm{BC}+$ in the first block of training. Summation on ABC- trials is only predicted by the modified unique cue theory but not by Pearce's configural theory.

\section{DISCUSSION}

Our experiments show that a modified version of the unique cue theory can account for compound processing in olfactory patterning conditioning in honeybees. Although the final outcome of a complex $\mathrm{A}+/ \mathrm{B}+/ \mathrm{C}+, \mathrm{AB}+/ \mathrm{AC}+/ \mathrm{BC}+$, $\mathrm{ABC}$ - discrimination task (Experiment 1) did not allow us to distinguish empirically between the unique cue and modified unique cue theories, on the one hand, and Pearce's configural theory, on the other hand, summation during $\mathrm{ABC}$ - presentation at the beginning of training contradicted Pearce's configural theory. The outcome of an A+, $\mathrm{BC}+, \mathrm{ABC}-$ discrimination task (Experiment 2), which was designed to differentiate between the unique cue and the modified unique cue theories, allowed us to discard the unique cue theory. Additionally, summation was also observed during $\mathrm{ABC}$ - presentation at the beginning of training, contradicting again Pearce's configural theory. The modified unique cue theory is thus the only theory that fully accounts for all our past and present results on olfactory compound processing in honeybees.

\section{Experiment 1: $\mathrm{A}+/ \mathrm{B}+/ \mathrm{C}+$ and $\mathrm{AB}+/ \mathrm{AC}+/ \mathrm{BC}+$ Versus $A B C-$}

According to the unique cue theory and the modified unique cue theory, differentiation between the binary compounds $\mathrm{AB}+/ \mathrm{AC}+/ \mathrm{BC}+$ and the ternary compound $\mathrm{ABC}-$ should develop faster than that between the single odors $\mathrm{A}+/ \mathrm{B}+/ \mathrm{C}+$ and the ternary compound $\mathrm{ABC}-$. Owing to summation of the single associative strengths of the elements $V_{\mathrm{A}}, V_{\mathrm{B}}$, and $V_{\mathrm{C}}$ in the binary compounds, responding to them should be stronger than to the single elements. According to Pearce's configural theory, however, differentiation between the binary compounds and the ternary compound should develop more slowly than between the single elements and the ternary compound because of higher gen- eralization between binary and ternary mixtures, which share more common elements.

Bees in our experiment tended to respond more to the reinforced single odors and to the binary mixtures than to the nonreinforced ternary compound. However, at the end of training there was no differentiation between single odors and mixtures. Because of this result, it was impossible to decide between the unique cue and the modified unique cue theories, on the one hand, and Pearce's configural theory, on the other hand. The lack of clear differentiation in this experiment could be explained by the high complexity of the task, because bees had to attend to seven different stimuli $(\mathrm{A}+, \mathrm{B}+, \mathrm{C}+, \mathrm{AB}+, \mathrm{AC}+, \mathrm{BC}+$, and $\mathrm{ABC}-)$ at the same time. Pigeons trained in autoshaping (Redhead and Pearce 1995) and humans conditioned with an eyelid conditioning procedure (Kinder and Lachnit 2003) had no difficulties in solving this task and showed clear response differentiation between reinforced and nonreinforced trial types. However, pigeons and humans received far more conditioning trials (pigeons, 216 trials; humans, 144 trials), whereas bees in the present experiment received only 48 conditioning trials with a total of 24 rewarded presentations (four rewarded presentations for each of the six reinforced stimuli) and 24 nonrewarded presentations of $\mathrm{ABC}$. In case of our Experiment 1, however, conditioning could not be extended to more trials for two main reasons. Firstly, increasing the number of trials may severely affect motivational levels in the appetitive paradigm of olfactory conditioning of the proboscis extension reflex. A higher number of reinforced trials may result in bees becoming satiated, as they usually got $\sim 1 \mu \mathrm{L}$ per reinforced trial, and the full capacity of their crop is $\sim 60 \mu \mathrm{L}$ (Núñez 1966). Under satiation conditions, bees do not respond in such an appetitive-conditioning paradigm. Secondly, reducing the intertrial interval in order to increase the number of trials without reaching satiation is also problematic, as we found that bees cannot solve negative patterning $(\mathrm{A}+, \mathrm{B}+, \mathrm{AB}-)$ with intertrial intervals shorter than 8 min (N. Deisig, J.-C. Sandoz, H. Lachnit, and M. Giurfa, unpubl.). This fact restricts the number of conditioning trials that could be applied in bees on a single experimental day. In an attempt to extend overall training time, we performed conditioning over two experimental days. However, the results showed that the overall responsiveness of bees already decreased during the first experimental day, and deteriorated during the second day. Thus, we think that methodological problems make such a long and complex discrimination task difficult to solve for bees.

Although the final outcome of differentiation in Experiment 1 did not allow distinguishing between the theories, we observed a summation effect at the outset of training. Summation occurs when responding to a compound (e.g., $\mathrm{AB})$ is stronger than responding to the elements that form the compound (e.g., A and B). Summation is explained by addition of the elemental associative strengths (e.g.,

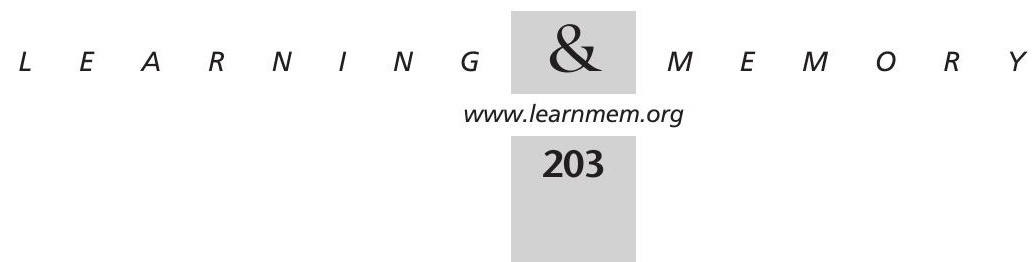


$\left.V_{\mathrm{A}}+V_{\mathrm{B}}\right)$ on compound trials. In the $\mathrm{A}+/ \mathrm{B}+/ \mathrm{C}+, \mathrm{AB}+/ \mathrm{AC}+/$ $\mathrm{BC}+, \mathrm{ABC}-$ discrimination, we observed at the beginning of training that responding to the ternary compound $\mathrm{ABC}-$ was considerably stronger than to the stimuli $\mathrm{A}+\mathrm{B}+/ \mathrm{C}+$ or $\mathrm{AB}+/ \mathrm{AC}+\mathrm{BC}+$. This finding indicates summation on $\mathrm{ABC}-$ presentation. This phenomenon was already observed in a wide range of conditioning preparations (see, e.g., Pavlov 1927; Reberg 1972; Kehoe 1986) and can easily be explained by the unique cue and the modified unique cue theories. However, Pearce's configural theory runs into difficulties with this observation (see below). Therefore, the results of Experiment 1 supported the unique cue and the modified unique cue theories but not Pearce's configural theory.

\section{Experiment 2: $A+$ and $B C+$ Versus $A B C-$}

Experiment 2 was conceived to allow further assessment of the different theories of compound processing. We used an $\mathrm{A}+, \mathrm{BC}+, \mathrm{ABC}-$ discrimination task that requires learning of only three different stimuli. Predictions of the unique cue theory and the modified unique cue theory differ for the course of differentiation between stimuli. According to the unique cue theory, response differentiation between the binary compound $\mathrm{BC}+$ and the ternary compound $\mathrm{ABC}-$ should develop faster than that between the single element $\mathrm{A}+$ and the ternary compound $\mathrm{ABC}-$, as summation of the single associative strengths of $\mathrm{B}$ and $\mathrm{C}\left(V_{\mathrm{B}}+V_{\mathrm{C}}\right)$ in the binary compound $\mathrm{BC}+$ should induce stronger responding to $\mathrm{BC}+$. In contrast, according to the modified unique cue theory, response differentiation between the single element $\mathrm{A}+$ and the ternary compound $\mathrm{ABC}-$ should develop faster than that between the binary compound $\mathrm{BC}+$ and the ternary compound $\mathrm{ABC}-$, as simultaneous occurrence of the two single stimuli $\mathrm{B}$ and $\mathrm{C}$ should distract their learning and should thus result in lower responding. Empirically, bees differentiated faster between the reinforced single odor A+ and the nonreinforced ternary compound $\mathrm{ABC}-$ than between the reinforced binary compound $\mathrm{BC}+$ and the nonreinforced ternary compound $\mathrm{ABC}-$. Thus, the outcome of the second experiment clearly rejected the predictions of the unique cue theory, but was consistent with the predictions of the modified unique cue theory. Interestingly, Pearce's configural theory makes the same predictions as the modified unique cue theory for this case. It predicts that response differentiation between the single odor $\mathrm{A}+$ and the ternary compound $\mathrm{ABC}$ - should develop faster than between the binary compound $\mathrm{BC}+$ and the ternary compound $\mathrm{ABC}-$ because of stronger generalization between the two latter stimuli. However, in this experiment, there was a clear summation effect during presentation of ABCat the beginning of training. This finding replicates the summation found at the beginning of training in Experiment 1 and is again at odds with Pearce's configural theory (see also Rescorla 1997).

\section{Summation}

In the $\mathrm{A}+, \mathrm{BC}+, \mathrm{ABC}-$ task, Pearce's configural theory cannot explain summation because responding to the ABCcompound should be based on generalization of associative strength of the element A+ and the binary compound $\mathrm{BC}+$. According to Pearce's view, generalization is based on the number of elements that $\mathrm{ABC}$ shares with $\mathrm{A}(1 / 3)$ and $\mathrm{BC}$ (2/3). Responding to $A B C-$ should therefore not exceed the level of responding to $\mathrm{A}+$ or $\mathrm{BC}+$. To predict summation, the configural theory has to appeal to the fact that conditioning always takes place in an experimental context (Pearce 1994; Aydin and Pearce 1997; Pearce et al. 1997), which can be associated with the US like any other stimulus. Assuming that the context $(\mathrm{X})$ is present throughout the experiment, the $\mathrm{A}+, \mathrm{BC}+, \mathrm{ABC}-$ training becomes an $\mathrm{AX}+$, $\mathrm{BCX}+, \mathrm{ABCX}-$ training, interspersed with $\mathrm{X}-$, as the context is present but not reinforced between trials. Pearce's model would then predict summation for ABCX- in a rather complex way (Rescorla 1997). Shortly, during training, the configural stimuli $\mathrm{AX}+$ and $\mathrm{BCX}+$ develop excitatory associative strength, while $\mathrm{X}-$ and $\mathrm{ABCX}$ - develop inhibitory associative strength. At any given time, responding to $\mathrm{ABCX}$ - reflects its own acquired associative strength, but also excitation generalized from $\mathrm{AX}+$ and $\mathrm{BCX}+$ as well as inhibition generalized from $\mathrm{X}-$. In comparison to Pearce's model without context influence, more excitation will be gained from $\mathrm{AX}+$ and $\mathrm{BCX}+$, than will be gained from $\mathrm{A}+$ and $\mathrm{BC}+$, because in the former case the stimuli have more elements in common. Most importantly, the inhibitory influence of the context $\mathrm{X}$, which also depends on the number of common elements, will be lower for ABCX- than for $\mathrm{BCX}+$ and for $\mathrm{AX}+$. Therefore, at one point during training, responses to $\mathrm{ABCX}-$ will be higher than responses to either $\mathrm{AX}+$ or $\mathrm{BCX}+$. Eventually, however, differentiation will lead to enough inhibitory associative strength for $\mathrm{ABCX}-$ so that responding to it will decrease and will be below responding to $\mathrm{AX}+$ and $\mathrm{BCX}+$. To visualize this fact, we carried out computer simulations of the $\mathrm{A}+, \mathrm{BC}+, \mathrm{ABC}-$ task, including a context $\mathrm{X}$ with different saliencies (see Fig. 3). We found that in order to reproduce the pattern of results observed in our experiment, the context $\mathrm{X}$ has to be more salient than the other stimuli (see Rescorla 1997 for a similar report). Varying the value of $\beta$, the learning rate associated with the US (see Materials and Methods), did not qualitatively change this result.

The crucial problem with the results of this simulation is that in general the context is viewed as less salient than the conditioned stimuli (e.g., Rescorla and Wagner 1972; Rescorla 1997). In line with this statement, the contextual surrounding of a harnessed bee trained in the paradigm of olfactory conditioning of the PER has limited influence on learning of the CS. It has been shown that when context exposure outlasts reward application as in our case, it cannot lead to excitatory memories for the context (Gerber and

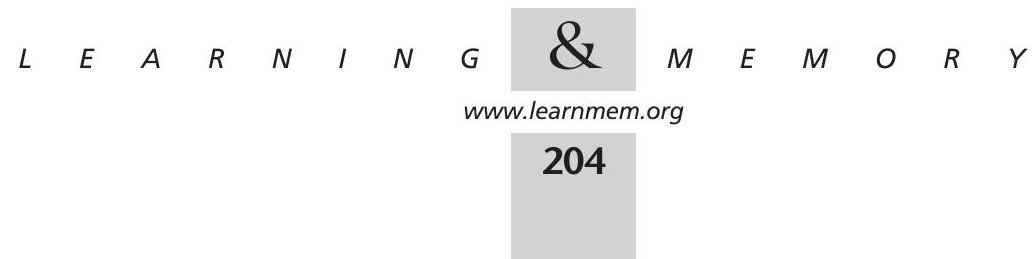




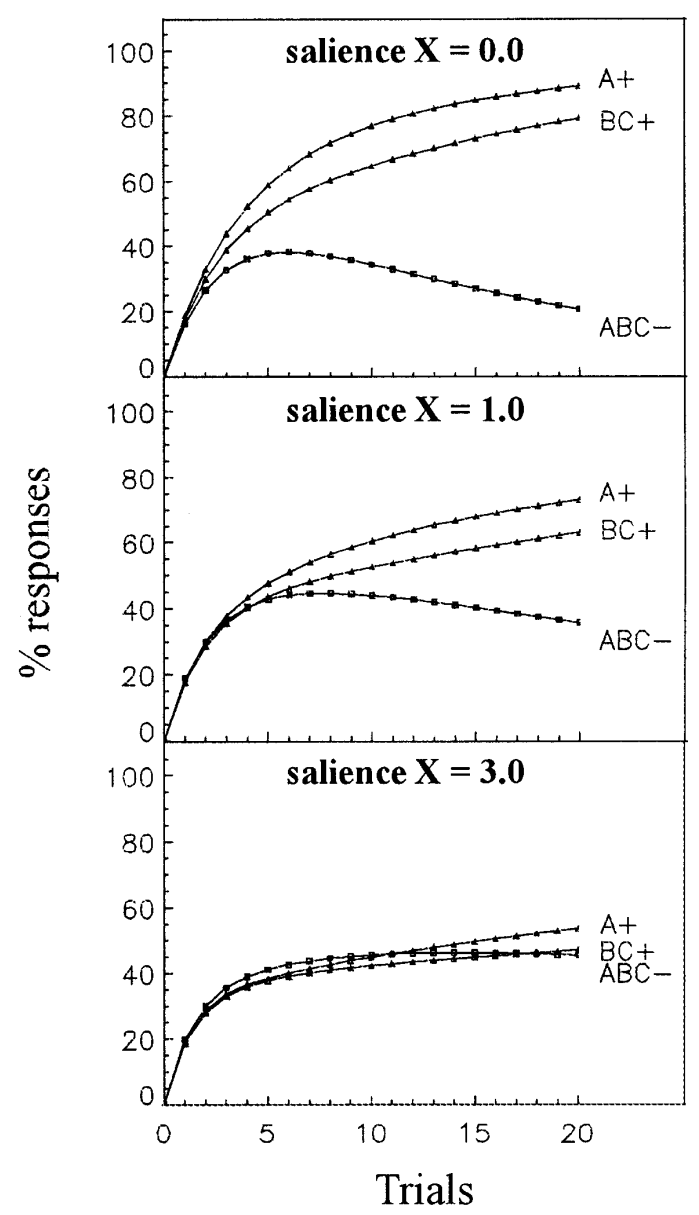

Figure 3 Computer simulation of an $\mathrm{A}+$ and $\mathrm{BC}+$ versus $\mathrm{ABC}-$ discrimination including a contextual stimulus $\mathrm{X}$ of three different saliencies along 20 trials. The learning rate associated with the US $(\beta)$ was 0.2 for reinforced trials and 0.1 for nonreinforced trials. The asymptotic level of associative strength $(\lambda)$ was 100 for reinforced trials and 0 for nonreinforced trials. Each cycle contained one trial with $\mathrm{A}+$, one trial with $\mathrm{BC}+$, and two trials with $\mathrm{ABC}-$. The salience of the context stimulus was varied from 0 to 3 . The upper panel shows the discrimination task in which the context had a salience of 0 (as if no context was present at all). The middle panel shows the same discrimination task including a context with a salience of 1 (salience equal to that of the other CSs). The lower panel shows the discrimination task including a context with a salience three times higher than that of the other CSs. Initial summation to $\mathrm{ABC}$ - can be observed only under this condition.

Menzel 2000). Furthermore, if the context would be a very salient stimulus present during CS-US pairings, then it should acquire associative strength, and thus responding to this salient context should be observable between conditioning trials at least at the beginning of training. This was never observed during our experiments. Therefore, in our experiments, the context can be ruled out as salient stimulus and can be considered as being much less salient than the olfactory stimuli. Thus, the only explanation that Pearce's configural theory can provide to explain summation has to be rejected in our case, which discards this theory in the case of olfactory compound processing in bees.

\section{The Modified Unique Cue Theory}

Our results strongly indicate that compound processing in bees occurs according to a modified unique cue theory. Such a theory not only explains the present experiments but can also account for all our previous results on learning of olfactory compounds by honeybees (Deisig et al. 2001, 2002). It assumes that compound processing relies on the use of a unique cue like that postulated by the unique cue theory (Rescorla 1972, 1973; Whitlow and Wagner 1972), but incorporates a correction for the reduced salience of components in a mixture due to interference between them (Mackintosh 1971; James and Wagner 1980). Such interference could be related to the fact that the associative strength that a US can convey in a given conditioning trial is limited, such that all CSs have to compete for it (Revusky 1971). Interference could also be related to an attentional process. Attentional theories assume that animals have only limited attentional capacity, so that attending to one CS will decrease the attention to, and learning about, another stimulus (e.g., Sutherland and Mackintosh 1971). Finally, it could be caused by a storage problem: Stimuli could compete for the maintenance of information in short-term memory even if they are independently well perceived (e.g., Atkinson and Shiffrin 1968; Norman 1968; Wagner 1976).

For the honeybee, interferences between olfactory stimuli were shown at the behavioral level with the overshadowing paradigm (Smith 1996; see above). These interferences can be retraced to different levels of processing (from peripheral to central). Elemental odors might already compete at the peripheral level for receptor sites or second messenger pathways. For instance, extracellular recordings from honeybees' placode sensillae revealed only equal or even less responding to binary compounds than to single odorants (Getz and Akers 1994). The peripheral olfactory system represents thus a nonlinear filter. At the central level, olfactory information is first processed at the level of the two antennal lobes, the primary olfactory neuropil of the bee brain. Each antennal lobe receives the information from $\sim 60,000$ olfactory receptors on each antenna via the antennal nerve. Each antennal lobe consists of 160 glomeruli, which are the functional processing units in which synaptic interaction takes place between incoming receptor neurons, local interneurons ( 4000), and projection neurons $(\sim 800)$, conveying information to the higher-order processing centers, the mushroom bodies. Optical imaging studies revealed that binary mixtures sometimes evoke patterns of glomerular activation that correspond to simple combinations of the constituent odorants (Joerges et al. 1997; Sachse and Galizia 2002). However, response intensities of the most responsive glomeruli showed inhibitory

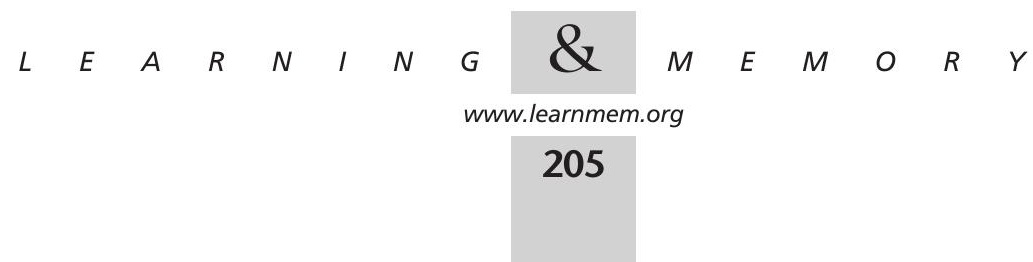


mixture interactions, which are probably caused by an inhibitory histaminergic network of local interneurons connecting glomeruli. Although such an effect has been demonstrated for odorants that are very similar (hexanol, octanol, nonanol; see Sachse and Galizia 2002), ternary mixtures involving similar and different odorants show such inhibitory interactions in a more accentuated way (Joerges et al. 1997). In that sense, the interactions between stimuli assumed by the modified unique cue theory could be simply a consequence of the intrinsic organization of the olfactory processing network with its inhibitory components (local interneurons) at the level of the antennal lobe. In any case, both peripheral and/or central interactions between odorants in a mixture could provide a relevant physiological basis for the assumptions of the modified unique cue theory.

\section{Compound Processing Theories and Animal Models}

This work provides strong evidence for a modified unique cue theory in the case of olfactory conditioning of the proboscis extension reflex in honeybees, that is, in a training procedure that uses stimuli of the same modality (olfactory). To our knowledge, the present work is the first report in which intramodal stimuli were used for modified patterning tasks and in which evidence is at odds with Pearce's configural theory. Further research seems necessary to investigate the reasons for the diverging results. Previous findings from experiments with human participants may provide some valuable hints for this search. Evidence from skin conductance conditioning experiments, for example, has shown that even intramodal stimuli might be processed very differently depending on their psychophysical properties (Lachnit 1988). Furthermore, prior experience may also influence whether a discrimination problem is solved elementally or configurally (e.g., Williams and Braker 1999; K. Lober, H. Lachnit, and D.R. Shanks, in prep.; K. Lober, H. Lachnit, M. Üngör, and D.R. Shanks, in prep.; M. Giurfa, M. Schubert, C. Reisenman, B. Gerber, and H. Lachnit, in prep.). The degree to which these factors may influence how stimuli are processed in honeybees and in other species deserves attention in future research. Free-flying bees could be a useful model for such research. Using bees that are not restrained in their behavior allows overcoming the limitation of PER conditioning in the sense that no manifestation of a conditioned response is visible in the case of harnessed bees whose PER is conditioned using visual stimuli. Furthermore, because free-flying honeybees can also be trained in patterning experiments with visual compounds (Schubert et al. 2002) and solve such patterning problems using nonelemental strategies, a next step should be to determine which nonelemental strategy (unique cue, modified unique cue, configural) is used by bees to solve these kind of problems. Additionally, to tackle the issue of intermodal versus intramodal in the case of stimuli used for conditioning (see above), experiments with free-flying bees using bimodal compounds (visual and olfactory) would also be possible.

\section{MATERIALS AND METHODS}

\section{Behavioral Experiments}

Honeybees (Apis mellifera L.) were caught at the entrance of outdoor hives at the beginning of each first experimental day. Each bee was immobilized by cooling in a freezer and then mounted into restraining harnesses such that it could only move the antennae and mouthparts, including the proboscis (Takeda 1961; Bitterman et al. 1983). Animals were then kept undisturbed in the experimental room in front of a constant airflow comparable to that of the odorsupplying device for $\sim 2 \mathrm{~h}$. Thus, familiarization with an airflow similar to that used in training was obtained such that mechanical airflow stimulation could not act as a predictor for the US.

Then, $10 \mathrm{~min}$ before the training on the first experimental day, each subject was checked for intact proboscis extension reflex by touching one antenna with a toothpick imbibed with sucrose solution without subsequent feeding. Extension of the proboscis beyond a virtual line between the open mandibles was counted as PER (unconditioned response). Animals that did not show the reflex $(<5 \%)$ were discarded before the experiments. Because experiments were performed over two experimental days, animals were fed to satiation $\sim 1 \mathrm{~h}$ after the training on experimental day 1 . This prevented them from starving until the next day. Overnight, they were kept in a covered plastic box with an imbibed tissue of water (to provide a certain humidity). On the second experimental day, bees that died during the night were removed $(<15 \%)$, and the remaining bees were again placed in front of the constant airflow besides the experimental device without subsequent feeding for 2 $\mathrm{h}$. The handling procedure on that day was similar to that on the first day.

The unconditioned stimulus (US) was always $1.25 \mathrm{M}$ sucrose solution, and the conditioned stimuli (CSs) were the three odorants limonene, 2-octanol, and methylsalicylate (Sigma). On each experimental day, $4 \mu \mathrm{L}$ of pure odorant was applied onto a fresh strip of filter paper. The paper strips were placed into a 1-mL plastic syringe and mounted in an odor-supplying device (Pelz et al. 1997). When the bee was placed in front of the device, it received a gentle, constant flow of clean air provided by a standard aquarium pump. Computer-driven solenoid valves (Lee Company) controlled airflow delivery. During periods of odorant delivery, the airflow was shunted through a syringe containing the odorant. In that way, a single odorant or a compound of two or three odorants was delivered to the bee. In the latter case, the valves corresponding to two or three different syringes were opened simultaneously such that the airflow arriving at the antennae of the bee contained two or three odors as a compound. An exhaust system behind the bees removed odor-loaded air. Between conditioning trials, bees were replaced in front of the small fan besides the odor-delivering device.

At the beginning of each trial the subject was placed in front of the odor-supplying device for $15 \mathrm{sec}$ to allow familiarization with the training situation. Thereafter, the CS was presented for $6 \mathrm{sec}$. In reinforced trials, the US onset occurred $3 \mathrm{sec}$ after CS onset. Both antennae were lightly touched with a toothpick imbibed with the sucrose solution, and after proboscis extension the bee was allowed to feed for $3 \mathrm{sec}$. Therefore, the interstimulus interval was 3 $\mathrm{sec}$, and the overlap between CS and US was also $3 \mathrm{sec}$. Nonrein-

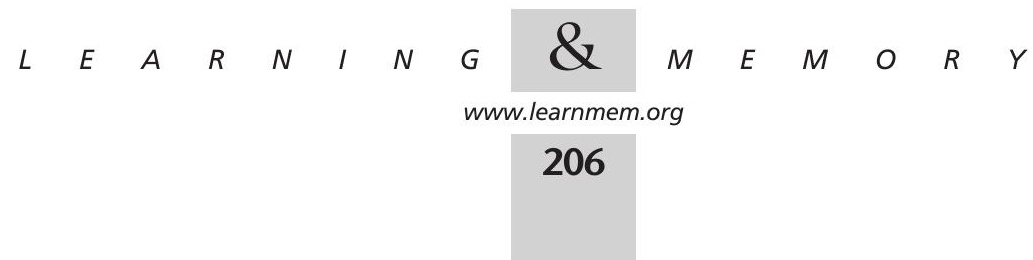


forced trials consisted of $6 \mathrm{sec}$ of CS presentation without reward. The intertrial interval was 8 min for all discrimination tasks.

During acquisition, we recorded whether a bee extended its proboscis in the $3 \mathrm{sec}$ after onset of the odor (CS) and, in the case of reinforced trials, before presentation of the sucrose solution (US). Thus, in such trials the PER recorded could not have been evoked directly by the US. The criterion for the occurrence of a conditioned response was the same as for the unconditioned one (extension of the proboscis beyond a virtual line between the open mandibles) except that it should occur in response to the olfactory stimulation. Multiple responses during a CS were counted as a single PER. Animals that never or always responded during conditioning were discarded for the analyses of data.

\section{Experimental Design}

Experiment 1: $\mathrm{A}+/ \mathrm{B}+/ \mathrm{C}+, \mathrm{AB}+/ \mathrm{AC}+/ \mathrm{BC}+, \mathrm{ABC}-$

The design of the first experiment was adopted from Redhead and Pearce (1995). A group of 39 bees was trained in a PER conditioning paradigm with an $\mathrm{A}+/ \mathrm{B}+/ \mathrm{C}+, \mathrm{AB}+/ \mathrm{AC}+/ \mathrm{BC}+, \mathrm{ABC}-$ discrimination task. Bees received a total of 48 training trials, with 4 presentations of each of the single elements $\mathrm{A}+, \mathrm{B}+$, and $\mathrm{C}+; 4$ presentations of each of the binary compounds $\mathrm{AB}+, \mathrm{AC}+$, and $\mathrm{BC}+$; and 24 presentations of the ternary compound $\mathrm{ABC}-$. Thus, each element was presented twice as often without reinforcement than with reinforcement. The number of training trials for the different types of stimuli was chosen to obtain the same number (24) of reinforced and nonreinforced trials. Training was performed over $2 \mathrm{~d}$. Accordingly, on each experimental day, single elements and binary compounds were presented only twice, whereas the ternary compound was presented 12 times. The sequence of CS+ and CS- trials was randomized and changed on each experimental day. The three odorants limonene, 2-octanol, and methylsalicylate were randomized as stimuli A, B, and C. The data are presented in 4 blocks of 6 trials for the ternary compound and in 4 blocks of 3 trials for single elements and binary compounds, respectively.

Experiment 2: $\mathrm{A}+, \mathrm{BC}+, \mathrm{ABC}-$

The design of the second experiment was also adapted from Redhead and Pearce (1995). For this experiment, a group of 39 bees was trained in a PER conditioning paradigm with an $\mathrm{A}+, \mathrm{BC}+, \mathrm{ABC}-$ discrimination task. Bees received a total of 24 training trials with 6 presentations of the single element A+, 6 presentations of the binary compound $\mathrm{BC}+$, and 12 presentations of the ternary compound $\mathrm{ABC}-$. The number of training trials for the different types of stimuli was chosen to obtain the same number (12) of reinforced and nonreinforced stimulus presentations. To match the experimental circumstances of Experiment 1, training was performed over $2 \mathrm{~d}$ with an intertrial interval of $8 \mathrm{~min}$. Accordingly, on each experimental day, the single element and the binary compound were each presented 3 times, whereas the ternary compound was presented 6 times. The sequence of CS+ and CS- trials was randomized and changed on each experimental day. The three odorants limonene, 2-octanol, and methylsalicylate were randomized as stimuli A, B, and C. The data are presented in 6 blocks of 2 trials for the ternary compound and in 6 one-trial blocks for the single element and the binary compound.

In both experiments, 16 bees were trained at the same time After discarding bees that died overnight and bees that responded always or never during the whole training, an average of 11 bees were trained per day. Accordingly, $4 \times 2 \mathrm{~d}(=8 \mathrm{~d})$ were necessary to train the bees in each experiment.

\section{Simulations}

Simulations including a context stimulus $(\mathrm{X})$ were performed for the second discrimination task $(\mathrm{A}+, \mathrm{BC}+, \mathrm{ABC}-)$. As the influence of the experimental context may qualitatively change the predictions of Pearce's configural theory, we performed simulations including a context stimulus $\mathrm{X}$ to which we assigned different saliencies. All simulations were performed with the interactive data language (IDL, Research Systems) using the following equation:

$$
\Delta V=\beta *[\lambda-(V+v)]
$$

where $\Delta V$ is the change in associative strength of a stimulus, $\beta$ is the learning rate associated with the US, $V$ is the associative strength of a stimulus ( $E$ in Pearce's formulations), and $v$ is the associative strength that generalizes to a pattern as a consequence of conditioning with other patterns. For all simulations, $\beta$ was 0.2 on reinforced trials and 0.1 for nonreinforced trials, and $\lambda$ was 100 for reinforced trials and 0 for nonreinforced trials. To match the experimental design, each cycle for the simulation contained one trial with $\mathrm{A}+$, one trial with $\mathrm{BC}+$, and two trials with $\mathrm{ABC}-$. According to Pearce, saliencies of stimuli are determined by generalization; thus, similarity factors (e) were assigned accordingly.

\section{Data Transformation and Statistical Analyses}

We measured the percentage of conditioned responses (\% PER) separately in successive CS+ trials (omitting the randomly interspersed CS- trials) and in successive CS- trials (omitting the randomly interspersed CS+ trials). For all groups, repeated-measure analyses of variance (ANOVAs) were used to analyze the data. Although ANOVA is usually not allowed in case of dichotomous data such as those of the PER, Monte Carlo studies have shown that it is permissible to use it under certain conditions (Lunney 1970), which were met by the two experiments reported here. Where necessary, Newman-Keuls tests were used to perform post hoc comparisons. The $\alpha$ level was set to 0.05 for all analyses.

\section{ACKNOWLEDGMENTS}

We thank Randolf Menzel for encouragement and valuable support. This work was supported by grants of the National German Science Foundation (DFG) to H.L. (DFG La 564/10-1, DFG La 564/10-3, DFG La 564/12-1, and DFG La 564/12-3) and Randolf Menzel (DFG Me 365/23-1) and by grants of the Programme Action Cognitique of the French Research Agency, the Fondation pour la Recherche Médicale (France), and the Human Frontier Science Program to Martin Giurfa.

The publication costs of this article were defrayed in part by payment of page charges. This article must therefore be hereby marked "advertisement" in accordance with 18 USC section 1734 solely to indicate this fact.

\section{REFERENCES}

Atkinson, R. and Shiffrin, R. 1968. Human memory: A proposed system and its control processes. In The psychology of learning and motivation: Advances in research and theory (ed. K. Spence ), Vol. 2, pp. 89-195. Academic Press, New York, NY.

Aydin, A. and Pearce, J.M. 1997. Some determinants of response summation. Anim. Learn. Behav. 25: 108-121.

Bahçekapili, H.G. 1997. "An evaluation of Rescorla and Wagner's elemenistic model versus Pearce's configural model in discrimination learning." Ph.D thesis. Yale University, New Haven, CT.

Bitterman, M.E., Menzel, R., Fietz, A., and Schäfer, S. 1983. Classical

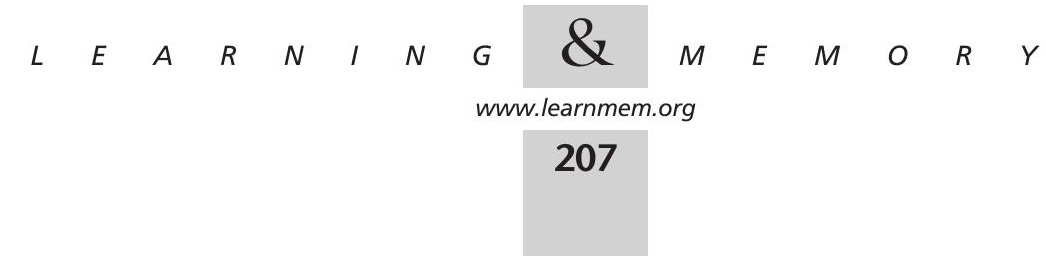


conditioning of proboscis extension in honeybees (Apis mellifera). $J$. Comp. Psychol. 97: 107-119.

Deisig, N., Lachnit, H., Giurfa, M., and Hellstern, F. 2001. Configural olfactory learning in honeybees: Negative and positive patterning discrimination. Learn. Mem. 8: 70-78.

Deisig, N., Lachnit, H., and Giurfa, M. 2002. The effect of similarity between elemental stimuli and compounds in olfactory patterning discriminations. Learn. Mem. 9: 112-121.

Gerber, B. and Menzel, R. 2000. Contextual modulation of memory consolidation. Learn. Mem. 7: 151-158.

Getz, W.M. and Akers, R.P. 1994. Honeybee olfactory sensilla behave as integrated processing units. Behav. Neural Biol. 61: 191-195.

James, J.H. and Wagner, A.R. 1980. One-trial overshadowing: Evidence of distributive processing. J. Exp. Psychol. Anim. Behav. Proc. 6: $188-205$.

Joerges, J., Küttner, A., Galizia, C.G., and Menzel, R. 1997. Representations of odors and odor mixtures visualized in the honeybee brain. Nature 387: 285-288.

Kehoe, E.J. 1986. Summation and configuration in conditioning of the rabbit's nictitating membrane response. J. Exp. Psychol. Anim. Behav. Proc. 12: 186-195.

Kinder, A. and Lachnit, H. 2003. Similarity and discrimination in human Pavlovian conditioning. Psychophysiology 40: 226-234.

Lachnit, H. 1988. Convergent validation of information processing constructs with Pavlovian methodology. J. Exp. Psychol. Hum. Percept Perform. 14: 143-152.

Lunney, G.H. 1970. Using analysis of variance with a dichotomous dependent variable: An empirical study. J. Educat. Meas. 7: 263-269.

Mackintosh, N.J. 1971. An analysis of overshadowing and blocking. Quart. J. Exp. Psychol. 23: 118-125.

Myers, K.M., Vogel, E.H., Shin, J., and Wagner, A.R. 2001. A comparison of the Rescorla-Wagner and Pearce models in a negative patterning and a summation problem. Anim. Learn. Behav. 29: 36-45.

Norman, D.A. 1968. Toward a theory of memory and attention. Psychol. Rev. 75: 522-536.

Núñez, J.A. 1966. Qualitative Beziehungen zwischen den Eigenschaften von Futterquellen und dem Verhalten von Sammelbienen. Z. vergl. Physiol. 53: 142-164.

Pavlov, I. 1927. Conditioned reflexes. Oxford University Press, Oxford, UK

Pearce, J.M. 1987. A model for stimulus generalization in Pavlovian conditioning. Psychol. Rev. 94: 61-73.

. 1994. Similarity and discrimination: A selective review and a connectionist model. Psychol. Rev. 101: 587-607.

Pearce, J.M. and Bouton, M.E. 2001. Theories of associative learning in animals. Ann. Rev. Psychol. 52: 111-139.

Pearce, J.M. and Redhead, E.S. 1993. The influence of an irrelevant stimulus on two discriminations. J. Exp. Psychol. Anim. Learn. Proc. 19: $180-190$

Pearce, J.M., Aydin, A., and Redhead, E.S. 1997. Configural analysis of summation in autoshaping. J. Exp. Psychol. Anim. Behav. Proc. 23: 84-94.
Pelz, C., Gerber, B., and Menzel, R. 1997. Odorant intensity as a determinant for olfactory conditioning in honeybees: Roles in discrimination, overshadowing and memory consolidation. J. Exp. Biol. 200: 837-847.

Reberg, D. 1972. Compound tests for excitation in early acquisition and after prolonged extinction of conditioned suppression. Learn. Mot. 3: 246-258.

Redhead, E.S. and Pearce, J.M. 1995. Stimulus salience and negative patterning. Q. J. Exp. Psychol. 48B: 67-83

Rescorla, R.A. 1972. "Configural" conditioning in discrete-trial bar pressing. J. Comp. Physiol. Psychol. 79: 307-317.

. 1973. Evidence for unique stimulus account of configural conditioning. J. Comp. Physiol. Psychol. 85: 331-338.

. 1997. Summation: Assessment of a configural theory. Anim Learn. Behav. 25: 200-209.

Rescorla, R.A. and Coldwell, S.E. 1995. Summation in autoshaping. Anim. Learn. Behav. 23: 314-326.

Rescorla, R.A. and Wagner, A.R. 1972. A theory of Pavlovian conditioning: Variations in the effectiveness of reinforcement and non-reinforcement. In Classical conditioning. II. Current research and theory (eds. A.H. Black and W.F. Prokasy), pp. 64-99. Appleton-Century-Crofts, New York, NY.

Revusky, S. 1971. The role of interference in association over delay. In Animal memory (eds. W.K. Honig and P.H.R. James), pp. 155-213. Academic Press, New York

Rowe, C. 1999. Receiver psychology and the evolution of multicomponent signals. Anim. Behav 58: 921-931.

Sachse, S. and Galizia, C.G. 2002. Role of inhibition for temporal and spatial odor representation in olfactory output neurons: A calcium imaging study. J. Neurophysiol. 87: 1106-1117.

Schubert, M, Lachnit, H., Francucci, S., and Giurfa, M. 2002. Nonelemental visual learning in honeybees. Anim. Behav. 64: 175-184.

Smith, B.H. 1996. The role of attention in learning about odorants. Biol. Bull. MBL 191: 76-83.

Sutherland, N.S. and Mackintosh, N.J. 1971. Mechanisms of animal discrimination learning. Academic Press, New York, NY.

Takeda, K. 1961. Classical conditioned response in the honey bee. $J$. Insect Physiol. 6: 168-179.

Wagner A.R. 1976. Priming in STM: An information-processing mechanism for self-generated or retrieval-generated depression in performance. In Habituation: Perspectives from child development, animal behavior, and neurophysiology (eds. T.J. Tighe and R.N. Leaton), pp. 95-128. Erlbaum, Hillsdale, NJ.

Whitlow, J.W. and Wagner, A.R. 1972. Negative patterning in classical conditioning: Summation of response tendencies to isolable and configural components. Psychon. Sci. 27: 299-301.

Williams, D.A. and Braker, D.S. 1999. Influence of past experience on the coding of compound stimuli. J. Exp. Psychol. Anim. Behav. Proc. 25: 461-474.

Received September 24, 2002; accepted in revised form March 13, 2003.

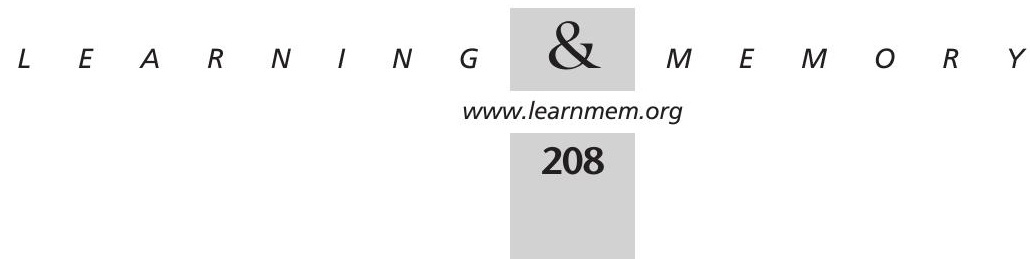




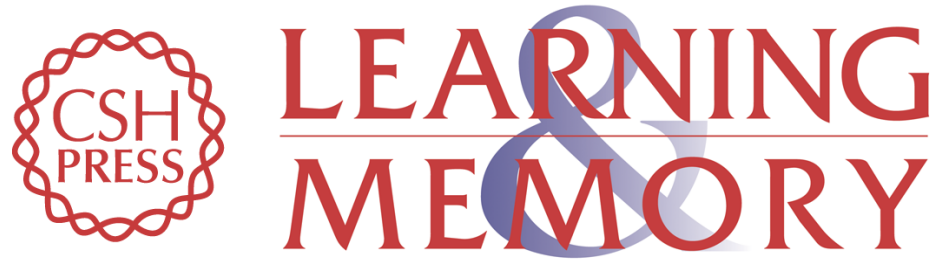

\section{A Modified Version of the Unique Cue Theory Accounts for Olfactory Compound Processing in Honeybees}

Nina Deisig, Harald Lachnit, Jean-Christophe Sandoz, et al.

Learn. Mem. 2003, 10:

Access the most recent version at doi:10.1101//m.55803

References This article cites 33 articles, 4 of which can be accessed free at:

http://learnmem.cshlp.org/content/10/3/199.full.html\#ref-list-1

License

Email Alerting Receive free email alerts when new articles cite this article - sign up in the box at the Service top right corner of the article or click here. 